\title{
EDUCACIÓN Y FORMACIÓN DE LA CIUDADANÍA: UNA VISIÓN DESDE LA CONFIGURACIÓN SOCIO-HUMANÍSTICA-SOSTENIBLE
}

\author{
Ysrael O. Márquez Ramírez \\ Universidad Nacional Experimental Simón Rodríguez, Venezuela
}

\begin{abstract}
Resumen.- El presente documento tiene como intención general, examinar los aspectos epistémico-gnoseológicos relacionados con el eje temático educación-ciudadanía y formación ciudadana. Se trata igualmente de una aproximación desde lo hermenéutico-interpretativo, que concibe la noción educativa como elemento clave para la formación de ciudadanos y ciudadanas en el contexto de los procesos de globalización planetaria y la redefinición de la sociedad en tiempos posmodernos. En este sentido, se manifiesta una postura en términos de una configuración socio-humanística sustentable que trata de interpretar las tendencias y acontecimientos educacionales y formativos con especial énfasis en la especificidad regional Latinoamericana y del Caribe. Desde estas líneas pre-orientativas, los fundamentos teóricoepistémicos trazan una diversidad de ejes de pensamientos que insertan el argumento en el debate actual acerca de la dimensión humana y la complejidad del pensamiento social contemporáneo. Un encuadre gnoseo-contextual abierto a la reflexión y a la construcción discursiva vinculante sobre el asunto de interés, que al mismo tiempo, toma en cuenta lo planteado por autores como Adela Cortina, Edgar Morín, Manuel Castells, Gabriel Parra, Gabriel Ugas y Magda Cejas; entre otros. En síntesis, esa red de pensamientos que se enlaza en las páginas proposicionales intenta emprender caminos hacia aquellos imaginarios connotados hacia la educación y formación de ciudadanos y ciudadanas desde la diversidad y la pluralidad histórico-cultural, así como revalorar la condición humana en términos multidimensionales, holísticos e integradores.
\end{abstract}

Palabras clave.- Aprendizaje, ciudadanía, educación, formación, sociedad, sustentabilidad.

Abstract.- This document has as a general purpose, to exam the epistemic gnoseologic aspects related to the theme of citizenship education and civic education. It is also an interpretationhermeneutic approach which conceived the notion of education as the key in formation of citizens at the context of the processes of globalization phenomenon and the global redefinition of society in postmodern times. In this sense, there is a position in terms of setting a sustainable sociohumanistic which seeks to interpret the trends and educational events and training with special emphasis on the specific regional, Latin American and Caribbean countries. Since these preorientation lines, the basis of theoretical epistemic plotted a variety of lines of thoughts that fit the argument in the current debate about the "human dimension" and complexity of contemporary social thought. A gnoseo contextual frame open to reflection and the discursive construction binding on the matter of interest, at the same time, taking into account the points made by authors like Adela Cortina, Edgar Morin, Manuel Castells, Gabriel Parra, Gabriel Ugas and Magda Cejas , among others. In short, this network of thoughts that are hyperlinked on propositional pages intends to engage roads to those renowned imaginaries towards education and training of citizens from the cultural-historical diversity and plurality as well as reassess the human condition in multidimensional terms, holistic.and.integrative.

Keywords.- Education, citizenship, learning, preparation, society, sustainability. 


\section{"La pluralidad es la condición de la acción humana debido a que todos somos lo mismo, es decir humanos, y por tanto nadie es igual a cualquier otro que haya vivido, viva o vivirá" Hannah Arendt ${ }^{1}$}

\section{Escenarios Complejos en la Era de la Globalización}

Cuando el ser humano se mira así mismo, mira también su entorno. En esa medida podrá comprender lo que define su existencia. La complejidad de los actuales eventos socio-humanos se entretejen no solo desde lo particular, sino que se extienden a lo general o viceversa. En este sentido, se puede afirmar que los fenómenos sociales, culturales, políticos, económicos o tecnológicos no dejan de perfilarse en la redefinición de los avances societales. Así, el "mensaje" en cualquiera de sus modalidades conjuga el poderío intrínseco para mostrarse en el ámbito de la importancia comunicativo-didáctica y el devenir humano-planetario.

Las palabras predelineadas introducen aspectos que se podrían vislumbrar desde ámbitos envolventes o contextuales. Desde allí, el fenómeno de la "globalización" puede derivar en grandes cambios o transformaciones en los cuales los ciudadanos y las ciudadanas se encuentran necesariamente involucrados. Y a la luz de una mirada cognitivo-vivencial podría interpretarse en acciones vinculadas ineludiblemente a las dimensiones "claves" o "estratégicas" del ámbito político, socio-económico, cultural, científico o tecnológico. En este sentido preparatorio, vale preguntarse: ¿puede algún fenómeno socio-envolvente alterar el ritmo natural de una sociedad?, ¿En que medida sus ciudadanos y ciudadanas podrían comprender los cambios y transformaciones desde una mirada socio-sustentable?, ¿Cuáles pueden ser los factores que delinean la socio-sustentabilidad en la época actual?

Tales condiciones no solo tiene la cara de la preocupación sino la cara de los riesgos y los peligros extensivos. Giddens $(2005)^{2}$ comenta que "Vivimos en un mundo donde los peligros creados por nosotros mismos son tan amenazadores, o más, que los que proceden del exterior. Algunos de ellos son verdaderamente catastróficos, como el riesgo ecológico mundial, la proliferación nuclear o el colapso de la economía mundial".

El "mundo" como la muestra el precitado autor luce como un escenario epocalabsorbente mediante el cual se ajustan los elementos temporales-espaciales en

${ }^{1}$ (2005) ARENDT, Hannah. La Condición Humana. Ediciones Paidòs Ibérica, S.A. Barcelona, España. Pàg.36.

2 (2005) GIDDENS, Anthony. Un mundo Desbocado. Los Efectos de la Globalización en Nuestras Vidas. Taurus. Grupo Santillana de ediciones S.A. Madrid, España. 
conjugación con las dimensiones propias del acontecer humano y las especificidades de cada región pueden derivar en situaciones transformadoras muy particulares. Con la siguiente declaración Ferrer (1996) ${ }^{3}$ focaliza su punto clave o estratégico y lo vincula con el fenómeno de la "globalización" en atención a los referentes de una sociedad inclinada a superar las adversidades:

"Nunca han sido mas importantes que en la actualidad las especificidades nacionales y la calidad de las respuestas de cada país a los desafíos y oportunidades de la globalización. La experiencia histórica y la contemporánea son concluyentes; solo tienen éxito los países capaces de poner en ejecución una concepción propia y endógena del desarrollo y, sobre esta base integrarse al sistema mundial."

En ese contexto, el autor también distingue dos esferas definitorias del fenómeno globalizador: "la real y la virtual". "La primera comprende el crecimiento del comercio mundial que se concentra actualmente en los bienes de mayor valor agregado y contenido tecnológico"4..., "la segunda abarca, por un lado, los extraordinarios avances en el procesamiento y la transmisión de la información y, por otro, la esfera financiera" ${ }^{5}$. En coincidencia con Giddens, estas dimensiones en especificidad se han comportado perversamente en el sentido de que el hombre mismo ha creado inestabilidades de impacto global. Vale mencionar aspectos como las crisis financieras de los países asiáticos en la década de los 80, así mismo, la proliferación de armas nucleares, ataques terroristas en algunas macropobladas ciudades del planeta y la destrucción del medio ambiente. En la actualidad, la recurrencia se hace presente bajo el halo de situaciones preocupantes debido a los nuevos colapsos de las economías globales a partir de la crisis del sistema financiero de los Estados Unidos de América. La iliquidez o quiebra de bancos hipotecarios privados (Washington Mutual, Bear Stearns, "WaMu", Seguros belgo-holandés Fortis, Freddie Mac, Fannie Mae) obligo a la administración gubernamental norteamericana a "intervenir" con la finalidad de evitar males mayores no solo de proyección local sino mundial. Esta necesaria y poco ortodoxa intervención de los entes financieros estatales como Secretaria del Tesoro Estadounidense, la Reserva Federal estadounidense y el Banco Central Europeo junto a sus homólogos suizo y británico anunciaron una extensión de sus acuerdos excepcionales, denominados "swap", todo ello, implementados para

\footnotetext{
${ }^{3}$ (1996)FERRER, Aldo. De Cristóbal Colon a Internet: América Latina y la Globalización, Buenos Aires, Fondo de Cultura Económica, $1^{\circ}$ Edición, Pág. 23.

${ }^{4}$ Ibídem. Pág. 13.

5 Ibídem. Pág. 14."La esfera financiera" la presenta el autor como un fenómeno esencialmente contemporáneo.
} 
enfrentar la crisis. ${ }^{6}$ Visto de esa manera, parece que los "controles" se han perdido y las situaciones se ven cada día en emergencias no solo de circunscripción local sino de extensividad mundial. Desde esa visión, Stiglitz (2003) ${ }^{7}$ resalta la importancia del acceso a la información y la apertura participativa en los procesos democráticos como factor clave de la dinámica socio-dimensional. "El secreto reduce la información de que dispone la ciudadanía y obstaculiza su capacidad para participar en forma significativa". Y agrega que:

"...las sociedades democráticas modernas, al conocer la importancia de la información para un gobierno eficaz, intentan proteger la libertad y la independencia de la prensa y procuran promover la creación de centros de investigación y universidades independientes, a fin de conseguir un control efectivo en muchas áreas. El problema es que a menudo los funcionarios del gobierno son la única o la mayor fuente de información relevante y oportuna. Si los funcionarios se ven obligados a guardar silencio, el público no dispone de otra fuente de información eficaz." Insiste el autor: "la apertura es una parte esencial del ejercicio publico del gobierno".

Con mayor atención, en América Latina y el Caribe el asunto se insertan también en esa compleja malla de acontecimientos por medio del cual su ámbito luce muy particular, ya que su devenir se ha configurado acompañado de la variedad de precedentes históricos que conectan de una forma u otra el contenido de las variantes perversas del problema en referencia. En esa dirección, las partes constructivas del proceso multidimensional humano en el contexto mundial se constituyen desde la diversidad y pluralidad fenoménica. Así por ejemplo, las conjugaciones socioculturales derivadas de Europa y África han mostrado y muestran raíces o modos de vida dentro de las complejidades propias de las diferentes culturas, costumbres y tradiciones. Una oleada de lo que se ha llamado "globalización cultural de la historia de América Latina" fulgura con persistencia, y al respecto señala el escritor Ferrer (1996) ${ }^{8}$ que: "La globalización no es un fenómeno reciente. Tiene exactamente una antigüedad de cinco siglos...". El autor se remonta en el tiempo para hurgar en los preludios de la conquista y colonización; y resalta que "El descubrimiento y la conquista del Nuevo Mundo fue el mayor acontecimiento de la expansión de ultramar de los pueblos cristianos de Europa a partir del siglo XVI. En Iberoamérica, las enfermedades importadas por

\footnotetext{
${ }^{6}$ EL NACIONAL. Portada. Economía. 26 de septiembre 2008 | 08:46 am - AFP Disponible: http://www.el-nacional.com/www/site/p contenido.php?q=nodo/46754 [Consulta, 2008, octubre 06.] ${ }^{7}$ (2003) STIGLITZ, Joseph. Sobre la Libertad, el Derecho a estar enterado y el Discurso Público: el papel de la transparencia en la vida Pública. En: La Globalización de los Derechos Humanos. Varios Autores. Oxford Amnesty Lectures. Oxford University Press. Traducción de Helena Recassens Pons. Madrid, España. Págs. 135-136

${ }^{8}$ (1996) FERRER, Aldo. De Cristóbal Colon a Internet: América Latina y la Globalización, Buenos Aires, Fondo de Cultura Económica, $1^{\circ}$ Edición, Pág. 55.
} 
los europeos contribuyeron, en el primer siglo de la conquista, al exterminio de la mayor parte de población nativa"9. Desde luego, la continuidad histórica ha marcados momentos diferenciales y dentro del orden mundial actual este fenómeno adquiere dimensiones distintas y más complejas que en el pasado.

Así los efectos o cambios derivados y heredados en América Latina y el Caribe no son de gran novedad, y se podría pensar que el pueblo latino-caribeño se ha entretejido vivencialmente con "el otro" y sus acontecimientos en momentos históricos particulares. La catástrofe en sus dimensiones especificas de un particular momento histórico deriva igualmente en situaciones definitorias sobre las civilizaciones interrelacionadas. Aquella que intentan dominar a través de un sistema impuesto culturalmente puede provocar algún tipo de transformación radical de la situación preexistente. Por ello, una sociedad deberá interpretar sus condiciones en las interrelaciones locales y globales. La aprehensión de los medios tecnológicos, educativos o formativos de sus ciudadanos o ciudadanas parece ser la clave para soportar o sustentarse en la aldea global. Un hipotético escenario que podría minimizar situaciones devastadoras.

En ese encuadre descriptivo-referencial, el impulso de los valores educativos como expresión del bienestar colectivo-local, regional o mundial parece ser interpelado de generación en generación. Cada sociedad ha tratado de distinguir, desde su propio ritmo convivencial, la diversidad de manejar los importantes asuntos relacionados con los específicos procesos educativos y formativos de sus actores sociales: ciudadanos y ciudadanas. Esta vinculación, aunque parezca superficial, no deja de maravillar a cualquiera cuando se manifiesta en hechos tangibles. Sin embargo, Parra (2006) ${ }^{10}$ afirma que las experiencia en América Latina y el Caribe en lo que respecta a reformas educativas en los últimos años "muestran un proceso que atiende a la tensión que originan las especificidades entrópicas de orden político, por una parte, y el contexto coyuntural marcado por los desafíos que suponen los reajustes macroeconómicos infocapitalista" y "...resultan insuficientes para resolver los nudos críticos que impiden lograr una educación de calidad".

Así, todos los actos de ciudadanía y su vinculación socio-sustentable en el marco de los procesos educativos-formativos han sido marcados por momentos de crisis predefinidos en momentos de desequilibrios y ajustes del devenir social. De allí que exista una profundo compromiso de convivencia a escala mundial y una profunda necesidad de revisar los aspectos definitorios para formar y educar al ciudadano y ciudadana tanto en la noción ética como en la noción de valores,

\footnotetext{
9 Ibídem. Pág. 57.

${ }^{10}$ (2006) PARRA, Gabriel. Educación, Reforma y Sociedad del Conocimiento. En: La Universidad se Reforma V. Colección Debate sobre la Reforma. UCV, ORUS, IESALC-UNESCO, UNESR. Caracas, Venezuela....Pág. 165.
} 
vistos integralmente en su acepción de "ciudadanía". Al respecto Márquez (2009) ${ }^{11}$ señala:

“...importante interrogarse sobre el papel que juegan los espacios sociales de aprendizaje y el de sus actores en el proceso direccional y orientador pertinente al asunto de la formación ciudadana y su ineludible permanencia en el tiempoespacio como garantía de vida terráquea. Igualmente valorativo, la disposición socio-formativa se levanta como punta de un iceberg que parece delinear y apuntalar la condición ciudadana hacia un nuevo reordenamiento civilizatorio y cuya clave primordial se ensambla desde la interconexión del ámbito educativo y societal, bajo la supervisión ineludible de una "nueva ética humana" que considere necesariamente la comprensión de la biodiversidad y la perdurabilidad de la vida en el escenario terrestre. No alejado éste del énfasis impulsivo sustentable ${ }^{12}$ de las relaciones socio-culturales y ambientalistas o de los valores humanos como asunto de integración socio-humano".

Desde allí, la formulación pasa ineludiblemente por otras interrogantes: ¿Cuáles serán los rasgos definitorios de una noción de ciudadano o ciudadana?, ¿Por qué se considera la educación y la formación como dimensiones-ejes necesarios para establecer los cimientos de los ciudadanos y ciudadanas ante las complejas situaciones del mundo de hoy?, ¿Cuáles serán las líneas que definen la necesidad de asumir un ética de sustentabilidad socio-humanística?

Ante las líneas precedentes resalta sin lugar a duda que la ciudadanía ${ }^{13}$, en su esencia connotativa y derivativa se conjuga en la noción "política". Sin embargo, su naturaleza misma no circunscribe a una dimensión limitada o univoca en términos jurídicos. Ella permite la codificación amplia en lo que se refiere a los

${ }^{11}$ (2009) MÁRQUEZ, Ysrael. Educación, Ciudadanía y Formación Ciudadana: Tendencias complejas hacia una configuración-humanística-sustentable. En Itinerarios de Investigación. Compilador Agustín Martínez. Programa de Estudios Postdoctorales. ISBN: 9789802880409. Universidad Nacional Experimental Simón Rodríguez. Núcleo Regional de Postgrado. Caracas. Venezuela (RB)

${ }^{12}$ El uso del término se remite a los años sesenta en los albores de la crisis moderna ambientalista. El uso connota su derivación etimológica del latín sustentāre, intens, de sustinēre que significa conservar algo en su ser o estado. Sostener algo para que no se caiga o se tuerza y en su adjetivación designa lo que se puede sustentar o defender con razones. Actualmente se enmarca desde una multidimensionalidad gnoseoepistémica que remite a la necesidad de vincularlo a lo humano, social, económico, cultural. Se habla hoy de la "Sustentabilidad ambiental", "Sustentabilidad Ecológica", "Sustentabilidad económica", "Sustentabilidad social".

${ }^{13}$ (2007) Según la Real Academia Española el término ciudadanía deriva en las nociones que se relacionan con la cualidad y el derecho ciudadano, el comportamiento propio de un buen ciudadano y el conjunto de ciudadanos de un pueblo o nación. Asimismo, el vocablo ciudadano o ciudadana deriva de las nociones relativas a la ciudad o habitantes de las ciudades antiguas o estados modernos como sujetos de derechos políticos que intervienen en el gobierno del país. 
Derechos Humanos ${ }^{14}$ con lo cual responde a una estrategia de formar ciudadanos y ciudadanas por medio de un conjunto de prácticas interrelacionadas que permite en primera instancia la movilidad social y gobernabilidad: "democracia radical".

Por ello, la connotación "jurídico-político" no muestra por si sola la sustantividad del asunto sino que predelinea aspectos desde un todo interrelacionado que configura la integralidad interactuante. Savater (2007) ${ }^{15}$ apuntala desde la interrelación socio-cultural de los seres humanos elementos de "integración y reconocimiento político", en tal sentido, señala que: "La coexistencia de igualdad de derechos de diferentes formas de vida no debe conducir a la segmentación. Por el contrario, requiere la integración de los ciudadanos -y el reconocimiento reciproco de sus pertenencias culturales-en el marco de una cultura política compartida".

Esa dimensión que se complejiza a propósito de las actualidades societales derivadas de las interconexiones globalizadas no se dislocan de la esencia humana y de lo socio-vivencial. El sentido humano desde lo social se realza en contextos complejos. La adjetivación en su denominación "compartida" necesariamente remite a la interacción humana. Y desde allí, Morin (1999) ${ }^{16}$ defiende la idea de lo "humano espiritual" como elemento fundamental en la interacción con "el otro"; con lo cual la multidimensionalidad se acentúa en sociocultural y bio-psico humano. La comprensión del "otro" como comprensión de si mismo fundamenta las vinculaciones y acciones en sociedad, y por ende, el accionar de los ciudadanos y ciudadanas: la ciudadanía en amplitudes de redefinición epocal. Entonces, es pertinente pensar que "la acción escolar pasa por educar al ciudadano(a) dentro y fuera de la escuela, lo que implica la posibilidad de fortalecer lo institucional, lo cotidiano y lo público". (Márquez,

\footnotetext{
${ }^{14}$ DECLARACIÓN UNIVERSAL DE LOS DERECHOS HUMANOS. Texto completo disponible en: http://www.un.org/spanish/aboutun/hrights.htm

${ }^{15}$ (2007) SAVATER, Fernando. La Vida Eterna. Editorial Ariel. Primera edición. Barcelona, España. Pág. 149.
}

16 (1999) MORIN, Edgar. Los Siete Saberes Necesarios a la Educación del futuro. Organización de las Naciones Unidas para la Educación, la Ciencia y la Cultura (UNESCO). Traducción Mercedes Vallejo-Gómez (Profesora de la Universidad Pontificia Bolivariana de Medellín-Colombia) con la contribución de Nelson Vallejo-Gómez y Françoise Girard. Paris, Francia. http:// www.bibliotecasvirtuales.com/biblioteca/Articulos/Los7saberes/index.asp. 
$2005)^{17}$. Desde tal perspectiva, "la misión supone, evidentemente, fe en la cultura y fe en las posibilidades del espíritu humano"18.

El panorama muestra no solo las variabilidades connotativas del asunto que preocupa sino que se arma también de complejidades que ameritan profundas reflexiones en el ámbito de lo socio-educativo, tanto Latinoamericano como Mundial. Resalta nuevamente la oportunidad de interrogar lo siguiente: ¿Cuáles serán los aspectos que podrían afectar la dinámica de los procesos educativos y de formación ciudadana en la sociedad globalizada? La respuesta a tal formulación no parece sencilla y podría tener múltiples vertientes que predibujan un estado de crisis socio-educativa a escala no solo en el ámbito regional sino a escala global. La situación del (la) ciudadano(a) de esta época parece signada no solo por las tensiones locales socio-políticas y económicas sino también por aspectos de orden cultural y civilizacional. La ritualidad de los eventos microelectrónicos, la velocidad y ubicuidad del electromensaje acelera cambios en el orden del pensamiento, y afecta necesariamente en la manera de entender lo que ocurre en el seno de la sociedad misma.

\section{Desarrollo Humano Sustentable: hacia la consolidación ciudadana en los Escenarios Latinoamericanos y del Caribe}

Merece dar importancia a las especificidades evaluativas de cada región o país en particular cuando se examina el eje temático Latinoamericano y del Caribe. Algunas atenciones sobre los resultados empíricamente tangibles pueden derivar en configuraciones y perfiles de los escenarios en los cuales se insertan necesariamente los ciudadanos y las ciudadanas. Un referencial que posibilita una aproximación relacionados con los aspectos pertinentes a los progresos en materia de gestión social se enmarca en El Índice de Desarrollo Humano (IDH). El Informe de Desarrollo Humano (2007-2008) ${ }^{19}$ define este instrumento categorial evaluativo como "...un indicador compuesto que mide el avance promedio de un país en función de tres dimensiones básicas del desarrollo humano, a saber: vida larga y saludable, acceso a conocimientos y nivel de vida digno. Estas dimensiones básicas se miden, respectivamente, según esperanza de vida al

17 (2005) MÁRQUEZ, Ysrael. Educación y Ciudadanía: Una visión antropoética postmoderna en el contexto del sistema educativo venezolano. Tesis Doctoral no publicada. Núcleo Regional de Postgrado Caracas. Universidad Experimental Simón Rodríguez. Caracas. Venezuela (RB). Pág. 233.

${ }^{18}$ (2006) MORIN, Edgar y Otros. Educar en la Era Planetaria. Editorial Gedisa. Barcelona, España. Pàg. 123.

19 (2007-2008) INFORME SOBRE DESARROLLO HUMANO. La Lucha Contra el Cambio Climático: Solidaridad ante un Mundo Dividido. Publicado por el Programa de las Naciones Unidas para el Desarrollo.(PNUD). www.undp.org.ar/docs/HDR_20072008_SP_Complete2.pdf , Pág. 227. 
nacer, tasa de alfabetización de adultos y tasa bruta combinada de matriculación en enseñanza primaria, secundaria y terciaria y producto interno bruto (PIB) per cápita en paridad del poder adquisitivo en dólares de Estados Unidos (PPA en US\$).

Por ejemplo, México ha sido uno de los países Latinoamericanos con significativos embates producto de las tendencias perniciosas del infocapitalismo mundial. Para contrarrestarlo asumió desde la década de los noventa cambios orientados a interpretar los acontecimientos mundiales junto a directrices en el ámbito local con el fin de recuperar la confianza de los ciudadanos. Esta iniciativa también se monta en los compromisos internaciones como por ejemplo los Objetivos de Desarrollo del Milenio (2008) ${ }^{20}$, asumidos desde el año 2000. México desde 1999 ha estado impulsando sus políticas gubernamentales hacia el logro de disminuir la pobreza y atender las necesidades mínimas de bienestar humano tomando en cuenta las directrices-bases mencionadas. En términos generales y según el Informe sobre Desarrollo Humano $(2001)^{21}$ ubicó a México en una categoría de desarrollo humano medio en ese mismo año y pasó a la categoría de desarrollo humano alto con 0,802 en el 2002, posteriormente, el Informe sobre Desarrollo Humano publicado en el año $2008^{22}$ mostró que el país se mantuvo para el año 2005 en su categoría con un índice de 0.829. Esos niveles muestran con evidencia perceptible los retos que ha asumido los gobiernos Mexicanos a favor del desarrollo social y humano.

Con base a lo señalado, las políticas en su conjunto han consolidado resultados tangibles desde la importancia de modelos abiertos a la flexibilidad y consistencia estratégica en una sociedad abierta a los cambios y a los ajustes derivados del entorno. La visión y misión compartidas de sus modos de vida con un profundo arraigo en las tradiciones no son contradictorias. Todo se alinea en consustanciadas valores democráticos derivados de acciones que consolidan su ciudadanía desde las bases educativas y formativas de sus ciudadanos hacia el impulso de transferencia a su entorno. Desde esa sinergia, sus políticas parece que han tratado de delinear la formación de sus ciudadanos hacia la

20 (2008) INFORME OBJETIVOS DE DESARROLLO DEL MILENIO. Erradicar la Pobreza. Objetivos de Desarrollo del Milenio, 2015. Naciones Unidas. Nueva York. EEUU. Disponible: http://mdgs.un.org/unsd/mdg/Resources/Static/Products/Progress2008/MDG Report 2008 Es.pdf.

${ }^{21}$ (2000- 2001) INFORME SOBRE DESARROLLO HUMANO. Poner el Adelanto Tecnológico al Servicio del Desarrollo Humano. PNUD. Publicación para el Programa de las Naciones Unidas para el Desarrollo. Ediciones Mundi-prensa, 2001. Barcelona, España.

22 (2007-2008) INFORME SOBRE DESARROLLO HUMANO. La Lucha Contra el Cambio Climático: Solidaridad ante un Mundo Dividido. Publicado por el Programa de las Naciones Unidas para el Desarrollo.(PNUD). Disponible: www.undp.org.ar/docs/HDR_20072008_SP_Complete2.pdf. Pág. 231. 
consolidación de macroprocesos vinculados tanto a la Educación como la capacitación continua y la gestión de proyectos estratégicos en los escenarios de dimensiones locales, regionales y globales.

Otro caso importante ha sido el de Chile pero con un perfil diferente al de México. Su diferencia se evidencia en su sostenida tendencia a mantenerse en el nivel alto de Desarrollo Humano. Sus políticas estatales-gubernamentales igualmente se han perfilado hacia la atención socio-educativa de sus ciudadanos y ciudadanas como clave fundamental del desarrollo humano. Comparativamente, Chile también ha estado implementando desde 1999 políticas orientadas a la "calidad formativa" de sus ciudadanos en el marco de la competitividad de la era global. Importante destacar que su interpretación de los desniveles de un sistema educativo aislado y descontextualizado, con altos niveles de pobreza, impulso innovaciones educativas y formativas para sus ciudadanos en concordancia con los lineamientos y compromisos asumidos. Un ejemplo de ello fue el programa de apoyo a las escuelas de mayor pobreza, Proyecto de las 900 Escuelas $^{23}$. La formación y valoración fueron aspectos importantes en la consolidación de sus logros nacionales. Es por ello que la calidad de la educación chilena y el sentido de su ciudadanía se muestran en los resultados de reconocimiento tanto regional como mundial. El ranking de competitividad ${ }^{24}$ mundial como los Informes de Desarrollo Humano evidencia de alguna manera que Chile luce entre los mejores de Latinoamérica, (Índice de Desarrollo Humano que se ubicó para el año 2005 en $0.829)^{25}$.

El panorama que envuelve a Venezuela no dista de ser considerado en el ámbito de las reflexiones. Algunos rasgos numéricos permiten igualmente mostrar la tendencia de Venezuela en lo que respecta a los logros alcanzados en materia de desarrollo humano. El Índice de Desarrollo Humano PNUD (2001) no difiere mucho del promedio de América Latina en su conjunto: un 0, 765 para 1999- Nivel Medio. Esto significa que el país ocupó el puesto número 61 entre 166 países en 2001; en el 2002 ocupó el puesto $68(0,778)$ entre 177 países; y en el 2003, ocupó el puesto $69(0,775)$ entre 175 países, según el Índice de Desarrollo Humano PNUD (2003) ${ }^{26}$. Venezuela logró un índice de 0,792 en el 2005 y ocupó el puesto

${ }^{23}$ (2005) MÁRQUEZ, Ysrael. Educación y Ciudadanía: Una visión antropoética postmoderna en el contexto del sistema educativo venezolano. Tesis Doctoral no publicada. Núcleo Regional de Postgrado Caracas. Universidad Experimental Simón Rodríguez. Caracas. Venezuela (RB)

24 (2001-2002) INFORME ANUAL DEL FORO ECONÓMICO MUNDIAL. Índices de Competitividad. Disponible: http://www.econosur.com/docoi/compet01.htm

25 (2007-2008) INFORME SOBRE DESARROLLO HUMANO. La Lucha Contra el Cambio Climático: Solidaridad ante un Mundo Dividido. Publicado por el Programa de las Naciones Unidas para el Desarrollo.(PNUD). Disponible: www.undp.org.ar/docs/HDR 20072008 SP Complete2.pdf. Pàg. 231.

${ }^{26}$ (2003) INFORME SOBRE DESARROLLO HUMANO. Los Objetivos de Desarrollo del Milenio: 
74 entre 177 países según el Informe del PNUD 2008 ${ }^{27}$. Aunque se aprecia una diferencia con tendencia positiva entre los índices, su situación no dibuja una tendencia significativa apreciable cuando se compara con países como Chile y México. A pesar de los esfuerzos sostenidos desde 1999, Venezuela continúa desde este marco informativo referencial conservando el nivel medio como categoría de ubicación en relación con la búsqueda del bienestar de sus ciudadanos en el posicionamiento de un nivel de desarrollo humano alto ${ }^{28}$.

\begin{tabular}{|l|l|l|l|}
\hline País & $\mathbf{1 9 9 9}$ & $\mathbf{2 0 0 1}$ & $\mathbf{2 0 0 5}$ \\
\hline Barbados & $0,864(\mathrm{~A})$ & $0,888(\mathrm{~A})$ & $0,892(\mathrm{~A})$ \\
\hline Chile & $0,825(\mathrm{~A})$ & $0,831(\mathrm{~A})$ & $0,867(\mathrm{~A})$ \\
\hline Costa Rica & $0,821(\mathrm{~A})$ & $0,832(\mathrm{~A})$ & $0,846(\mathrm{~A})$ \\
\hline Cuba & $i ?$ & $0,806(\mathrm{~A})$ & $0,838(\mathrm{~A})$ \\
\hline México & $0,790(\mathrm{M})$ & $0,800(\mathrm{~A})$ & $0,829(\mathrm{~A})$ \\
\hline Panamá & $0,790(\mathrm{M})$ & $0,788(\mathrm{M})$ & $0,812(\mathrm{~A})$ \\
\hline $\begin{array}{l}\text { Trinidad } \\
\text { Tobago }\end{array}$ & $0,798(\mathrm{M})$ & $0,802(\mathrm{~A})$ & $0,814(\mathrm{~A})$ \\
\hline
\end{tabular}

Tabla 1. Índices de Desarrollo Humano: Tendencias de algunos países de América Latina y el Caribe.

un pacto entre las naciones para eliminar la pobreza. PNUD. Publicación para el Programa de las Naciones Unidas para el Desarrollo. Ediciones Mundi-prensa, 2003. Barcelona, España.

27 (2007-2008) INFORME SOBRE DESARROLLO HUMANO. La Lucha Contra el Cambio Climático: Solidaridad ante un Mundo Dividido. Publicado por el Programa de las Naciones Unidas para el Desarrollo.(PNUD). Disponible: www.undp.org.ar/docs/HDR 20072008 SP Complete2.pdf.

${ }^{28}$ Vale destacar el logro alcanzado para el 2006. Según el informe estadístico (HDI-a statistical update 2008) del PNUD, Venezuela alcanzó un índice de $\mathbf{0 . 8 2 6}$ ubicándose en el puesto 61 entre 179 paises. Actualización referencial 2009 en atención que para la fecha de redacción del presente documento no se había publicado el informe respectivo PNUD. Disponible:

http://hdr.undp.org/en/statistics/data/hdi2008/. [consulta: 2009, octubre 14] 


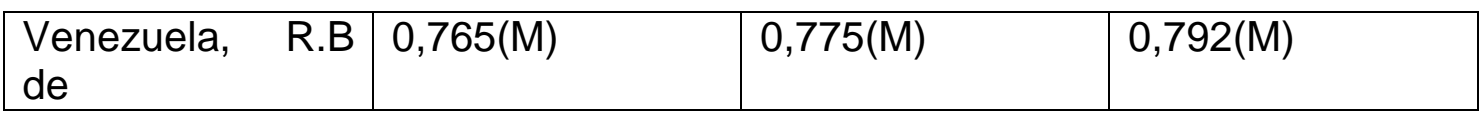

Leyenda: (A) Índice de Desarrollo Humano Alto, (M) Índice de Desarrollo Humano. El Índice Promedio de Desarrollo Humano de América Latina y el Caribe en 1999, 2001 y 2005 fue de $0,760(M) ; 0,777(M)$ y 0,803(A) respectivamente.

Fuente: INFORME SOBRE DESARROLLO HUMANO (2007-2008). La Lucha Contra el Cambio Climático: Solidaridad ante un Mundo Dividido, INFORME SOBRE DESARROLLO HUMANO (2003). Los Objetivos de Desarrollo del Milenio: un pacto entre las naciones para eliminar la pobreza, INFORME SOBRE DESARROLLO HUMANO (2000-2001) Poner el Adelanto Tecnológico al Servicio del Desarrollo Humano.

Pero en contraste a la descripción comparativa anterior es importante señalar como Venezuela ha perfilado un camino alentador en lo que respecta a disminuir los índices de pobreza en atención a los Objetivos de Desarrollo del Milenio ${ }^{29}$. Muy similar a los logros de México, Venezuela ha perfilado una tendencia favorable al disminuir sus tazas de pobreza e indigencia. Desde el año 2002 su índice se consolida hacia la baja de 18,4 a 12,3 puntos porcentuales entre 2002 y 2006 respectivamente. La elevada taza de crecimiento del producto, así como la implementación continua de programas sociales de gran amplitud permitieron que tan solo entre el 2002 y el 2006 la taza de pobreza pasara de 48,6\% a un 30,2\% y la indigencia pasara de un $22,2 \%$ a un $9,9 \%$. Este acelerado avance señala una mejora sustantiva de las perspectivas de reducción de la pobreza e indigencia e incrementa significativamente la probabilidad de cumplir con la primera meta del milenio. ${ }^{30}$ De esta perspectiva, los conjugados esfuerzos podrían responderle a la ciudadanía venezolana en lo que respecta a elevar sus niveles de desarrollo humano, sin embargo, pareciera que estos no se vislumbran con ahínco estratégico y sustentable cuando se enmarcan en términos evaluativos globales.

Por otra parte, los macro-indicadores estadísticos que se obtienen del Informe de Los Objetivos de Desarrollo del Milenio apuntan hacia logros muy alentadores en lo relativo a la expansión positiva de la escolaridad en los diferentes países adscritos a tal compromiso global. Latinoamérica y el Caribe han consagrado índices por encima de la media esperada, mayor al 60\%. Por ejemplo, las

${ }^{29}$ (2008) INFORME OBJETIVOS DE DESARROLLO DEL MILENIO. Ocho objetivos: Erradicar la Pobreza Extrema y el Hambre, Lograr Enseñanza Primaria Universal, Promover la Igualdad de Genero y el Empoderamiento de la Mujer, Reducir la Mortalidad Infantil, Mejorar la Salud Materna, Combatir el VIH/Sida, el Paludismo y otras Enfermedades; Garantizar la Sostenibilidad del Medio Ambiente, Fomentar una Alianza Mundial para el Desarrollo. Disponible: http://mdgs.un.org/unsd/mdg/Resources/Static/Products/Progress2008/MDG Report 2008 Es.pdf

${ }^{30}$ (2007) DOCUMENTO INFORMATIVO. Panorama Social de América Latina. Naciones Unidas, CEPAL. Disponible: www.derechoshumanosbolivia.org/informes/Panorama\%20Social.pdf. Pág. 11. 
categoría relacionada con niños excluidos del sistema escolar se ubico en el año 2006 en 16\%, niños que asisten a la enseñanza primaria 18" y la secundaria 67\%. Estos indicadores muestran el avance significativo cuando se comparan con años anteriores. Sin embargo, "lograr la educación primaria universal implica más que la cobertura total de la matricula. Abarca también educación de calidad lo cual significa que toda la población infantil que asista a la escuela en forma regular, aprenda habilidades básicas de lecto-escritura y matemáticas y finalice a tiempo la escuela primaria"31.

Un ejemplo subsiguiente podría manifestar contundencia reflexiva en lo relativo a las habilidades de comprensión lectora y la calidad de los proceso de educativoformativo, igualmente, permite inferir la necesidad de atender con estrategias agresivas al asunto que debilita los logros que se obtienen en las categoría de inserción escolar. En atención a ello, parece pertinente señalar:

“...los resultados de la prueba de comprensión lectora del Programa Internacional de Evaluación de Estudiantes (PISA), aplicada por la Organización de Cooperación y Desarrollo Económicos (OCDE) en 43 países, en los países latinoamericanos que participaron (Argentina, Brasil, Chile, México y Perú) se obtuvieron, en general, las peores distribuciones de resultados: el porcentaje de estudiantes que no superó el nivel 1 de exigencias (de un total de 5 niveles) en los 27 países de la OCDE se acercó al 15\%; en 11 países de otras regiones (principalmente Asia) llegó al 45\% mientras que en América Latina superó el 54\%.19 Dado que la heterogeneidad de resultados en cada país refleja, en parte, la variedad de grados o niveles educativos que cursan los educandos a una determinada edad, se optó por seleccionar estudiantes de un solo nivel educativo, el décimo grado, que generalmente corresponde al último año del ciclo inferior de secundaria" ${ }^{32}$.

A propósito de la descripción anterior y los argumentos relacionados con la "calidad educativa" que se leen en el Documento informativo del Panorama Social de América Latina $(2007)^{33}$, resulta muy importante destacar las dimensiones que deberán tomarse en cuenta para logros consustanciados con el desarrollo humano sustentable, al respecto se cita:

${ }^{31}$ (2008) INFORME. OBJETIVOS DE DESARROLLO DEL MILENIO. Naciones Unidas. Nueva York. EEUU. Disponible: http://mdgs.un.org/unsd/mdg/Resources/Static/Products/Progress2008/MDG Report 2008 Es.pdf. Pàg 14.

32 (2007) Documento Informativo del Panorama Social de América Latina. Naciones Unidas. Comisión Económica para América Latina y el Caribe. Pág. 44.

${ }^{33}$ Ibídem. Pág. 39. 
"la marcada expansión de la cobertura educativa, que en algunos países alcanza la totalidad de la población en edad escolar. Es uno de los avances destacables en este sector en las últimas décadas y es el resultado de políticas sociales y educativas activas, que han significado muchas veces transformaciones de las formas de gestión de los sistemas educacionales, aumentos presupuestarios sostenidos, diversificación de los esquemas de financiamiento y de participación de los agentes económicos y actores sociales, entre otras medidas. Sin embargo, los logros no han sido similares en las distintas esferas de la educación, lo que ha mostrado las insuficiencias respecto de la calidad de la educación. En buena medida, los diversos problemas relacionados con la calidad y otras dificultades del sistema educativo (retención y repetición, deserción escolar) son expresiones de una situación mucho más profunda y arraigada en América Latina: la desigualdad social. Asegurar una educación de calidad para todos supondría un proceso de inclusión a lo largo de la vida (en el que se respetara el derecho a la educación, la igualdad de oportunidades y la participación) que brinde las herramientas para enfrentar los diferentes obstáculos que excluyen o discriminan a los estudiantes, como los que limitan su aprendizaje y su pleno desarrollo como personas. Una educación de calidad para todos, además de responder a una exigencia de equidad, debe ser relevante y pertinente".

Las acciones de orden estratégicos deberán orientarse hacia la "integralidad y calidad"; desde una visión que estime la totalidad de la ciudadanía y sus posibilidades de autonomía y sustentabilidad socio-productiva. La posibilidad de participación en los contenidos del todo nación supone su inscripción en el marco de los derechos humanos y ciudadanos y de la participación en la plataforma integral de los escenarios socio-políticos, económicos o cualquier otro de interés público, ya que la preocupación de la ciudadanía esta fundada en hechos reales. En tal sentido, Bernardo Kliksberg (2005) ${ }^{34}$ afirma que "una pregunta recorre la América Latina en esperanzador proceso democrático, y suena con fuerza creciente en manos de la ciudadanía cada vez más participativa" y se pregunta al respecto: ¿cuáles son las causas de que un continente con tantas riquezas potenciales, y con realizaciones tan significativas, tenga los altísimos niveles de exclusión social que lo caracterizan?

El asunto no parece muy sencillo de responder en el entendido que los modos de pensar y participar se complejizan a propósito de la diversidad y particularidades del fenómeno globalizador. Bajar los índices de pobreza no solo significa suministrar recursos mediantes instrumentos de atención social generalizada y descontextualizadas. En todo caso, la inclusión social puede involucrar procesos bien definidos y de alto impacto resolutivo a corto, mediano y largo plazo junto a estrategias que consideren los aspectos de sustentabilidad socio-productiva

\footnotetext{
${ }^{34}$ (2005) KLIKSBERG, Bernardo. La Agenda Ética Pendiente de América Latina. Primera
} Edición, Fondo de Cultura Económica de Argentina, S.A. Introducción. Pág. 27. 
consensual desde lo gubernamental-estatal-sociedad. Esa línea proyectiva puede estar orientada a asumir la corresponsabilidad y la fraternidad con el fin de disminuir la perversidad que induce los altos niveles de pobreza a escala mundial. Desde esa perspectiva, las claves parecen de orden político para lo cual Ferrer (2001) ${ }^{35}$ impulsa su idea de "alianzas de las fuerzas políticas y sociales" y al respecto expresa que:

“...es indispensable la recuperación de la capacidad de decisión del sector público y una reforma auténtica del Estado para convertirlo en protagonista efectivo del cambio y socio imprescindible de la iniciativa privada. Son indispensable alianzas entre las principales fuerzas políticas y sociales para sustentar el cambio de rumbo y marchar hacia la meta de la estabilidad y el desarrollo sostenible"

La comprensión hacia el fin común luce ineludible y esas alianzas de fuerzas serán primigenias a favor de los más débiles socialmente cuando lo humano se asuma como valor universal. Se trata en fin de una "ciudadanía que vaya más allá de la búsqueda del bienestar y se proponga reconfigurar y realzar el valor de los sueños, de la voluntad utópica y la felicidad humana"36.

\section{República Bolivariana de Venezuela: Aproximaciones al contexto socio- educativo y la Formación de sus Ciudadanos y Ciudadanas}

Durante la década de los años `80 y los primeros años de los `90, la República de Venezuela se vio obligada a asumir también los retos de impulsar nuevos esquemas y modelos para iniciar las reformas pertinentes. En el ámbito del sistema escolar se propuso una reforma educativa bajo los lineamientos del documento Currículo Básico Nacional de 1998: "El nuevo modelo curricular, base de la reforma educativa se sustenta en la transversalidad. Algunos elementos distorsionantes acentuaban los bajos niveles de logros en lo que respecta al escenario educativo. Entre ellos se pueden señalar: "(1) El uso del sistema educativo como instrumento para clientelismo político; (2) El descuido de los niveles básicos de educación, tanto en calidad como en lo que respecta a formar para mejorar la oferta y demanda de empleos productivos y la educación para la participación democrática; (3) La falta de autonomía de las escuelas, que ha

${ }^{35}$ (2001) FERRER, Aldo. Vivir lo nuestro, nosotros y la Globalización. Colección Popular 617. Serie Breves. Fondo de Cultura Económica. Buenos Aires Argentina. Pág. 81.

${ }^{36}$ (2008) PARRA, Gabriel. .Educación, Reforma y Globalización. Discurso-ponencia en VI Congreso de Investigación. Universidad de Carabobo. La investigación en el Siglo XXI: Oportunidades y Retos. Valencia, Estado Carabobo. Venezuela. 
impedido a los directores y docentes coordinar sus tareas con la comunidad educativa, a los fines de generar respuestas pertinentes en lo social" ${ }^{37}$.

Con base a los indicadores preseñalados se concentra el mayor esfuerzo en una nueva configuración nacional. El ascenso al poder del Presidente Hugo Chávez en 1999 predelineó un debate cuyo punto de partida fue el plano jurídicoconstitucional y el centro de gravitación fue la dimensión "formativa" del nuevo ciudadano venezolano. En esa dirección "lo educativo se inserta entonces en una nueva perspectiva: se trata del rescate de la dignidad del ciudadano como fundamento del aprendizaje social. Este es el principal eslabón del Proyecto Educativo Nacional (PEN)"38

Hoy, el proceso educativo venezolano proyecta una educación para la ciudadanía bajo los principios rectores de la praxis socio-comunitaria e ideales bolivarianos, amén, de trazar una búsqueda en la reflexión pertinente con los propósitos de la dimensión socio-formadora y educativa en el nuevo contexto complejo-envolvente: "ideologizante-doctrinario". Esta relación conceptual e inclinación pulsante hacia un modo particular de pensar el país, en el ámbito de las políticas gubernamentales y la configuración nacional de la sociedad venezolana en general, ha generado controversiales discusiones. Por ello, se puede estimar pertinente predefinir ambos connotantes lingüísticos. Según la Real Academia Española ${ }^{39}$ Ideología deriva lingüísticamente del griego íঠ́ca, idea, y -logía que refieren a doctrina filosófica centrada en el estudio del origen de las ideas o es el conjunto de ideas fundamentales que caracteriza el pensamiento de una persona, colectividad o época, de un movimiento cultural, religioso o político, etc. Por otra parte, Doctrina deriva lingüísticamente del lat. Doctrīna que refiere a la enseñanza que se da para la instrucción de alguien o conjunto de ideas u opiniones religiosas, filosóficas, políticas, etc., sustentada por una persona o grupo. Ej. Doctrina cristiana, tomista, socialista.

El primer término lingüístico relacionado presenta dos vertientes significantes, una relacionada con el estudio epistemológico del término en si y el otro con relacionado con la especificidad definitoria de un pensamiento que puede permitir la organización de un grupo o sociedad. El segundo término también deriva dos vertientes significantes, una la relaciona con los aspectos de la enseñanzainstrucción con "fines específicos" en materias determinadas y la otra enlaza esta

${ }^{37}$ (2002) REIMERS, Fernando. Educación y Democracia: El caso de Venezuela. Instituto para el Desarrollo Internacional en la Universidad de Harvard. Documento en Línea. Disponible: http://.iacd.oas.org/la\%20Educa\%20116/reimers.htm. [Consulta: 2004, marzo 09]. Págs. 2-3.

${ }^{38}$ (2005) MÁRQUEZ, Ysrael. Educación y Ciudadanía: Una visión antropoética postmoderna en el contexto del sistema educativo venezolano. Tesis Doctoral no publicada. Núcleo Regional de Postgrado Caracas. Universidad Experimental Simón Rodríguez. Caracas. Venezuela (RB).

${ }^{39}$ (2008) REAL ACADEMIA ESPAÑOLA. Disponible: http://www.rae.es/rae.html. 
connotación en la especificidad de ideas o creencias de un "grupo o persona particular". Ahora en el marco relacional del término y su vinculación con el ámbito educativo, las diferenciaciones las hace Albornoz (2005) ${ }^{40}$ y señala que el "sistema educativo es ideológico, pero no todo sistema educativo es doctrinario". Vale aclarar que la "ideología" entonces se sustenta en forma específica en el conjunto de ideas e intereses compartidos mientras que la "doctrina" se manifiesta por el conjunto de ideas que unifican en profeso a un grupo. Desde esta distinción conceptual, el sistema educativo venezolano actual trata de propulsar los elementos doctrinarios desde lo ideológico con lo cual puede asomar contradicciones evidentes.

Hoy, en la educación venezolana se representan intereses políticos y doctrinarios en relación con su especificidad idearia "bolivariana-socialista", es decir, la educación venezolana se convierte en parte del "modelo autoritario" impuesto por "el aparato ideológico-militar del Estado" (Albornoz, 2001) ${ }^{41}$. Según este investigador, en Venezuela "la educación siempre ha sido ideológica pero no doctrinaria". Esta premisa fundamenta de alguna manera la sustentabilidad social y educativa desde la pluralidad cultural y la diversidad del pensamiento humano. Junto a esta premisa se desarrolla lo que Ugas (2005) ${ }^{42}$ enfatiza desde lo culturalcivilizacional:

"El clima cultural y la atmósfera civilizatoria tiende a globalizar el despliegue discursivo que conjuga lo social y lo escolar en el desarrollo vital-cognoscitivo. Acciones y pensamientos son determinados por circuitos educativos incidentes en los ciudadanos. Los circuitos sociales (familia, barrio, ciudad, región) condicionan la racionalidad epocal, operan como nudos temáticos de lo social-educativo configurado en una red semiótica que aporta contenidos articulados en el sistema, conformando temas transversales que operan como nutrientes de la racionalidad epocal"

Desde este precedente teórico, lo inductivo-aplicativo se transfiere a lo cotidiano y formal. Así, lo educativo-formativo luce pertinente para construir y reconstruir relaciones sociales con fines de la sustentabilidad humana en ámbitos de consenso y armonía humana. A partir de estas premisas, la "racionalidad epocal" apela necesariamente a los elementos de la construcción equilibrada de los

\footnotetext{
40 (2005) ALBORNOZ, Orlando. El Estado Docente no es Invasor sino Regulador. Entrevista a Orlando Albornoz realizada por Gustavo Méndez. En línea: eluniversal.com. Disponible: http://www.eluniversal.com/2005/07/06/pol art 06144A.shtml. [Consulta: 2007, octubre 31]
}

41 (2001) ALBORNOZ, Orlando. La Reforma de la Educación Superior y la Revolución Bolivariana. Caracas: Universidad Central de Venezuela, Facultad de Ciencias Económicas y Sociales, $383 \mathrm{p}$.

${ }^{42}$ (2005) UGAS, Gabriel. Epistemología de la Educación y la Pedagogía. Ediciones del Taller Permanente de estudios epistemológicos en Ciencias sociales San Cristóbal, 2003. Táchira, Venezuela. Pág. 140 
democráticos escenarios de interacción social a favor de la "buena" proyección del "bien social". Foucault (2005 $)^{43}$ invoca a la racionalidad del gobierno e indica con base en las ideas de Plutarco que "no se podría gobernar si no se es gobernado uno mismo. Pero ¿quién debe pues dirigir al gobernante? La Ley, seguro; sin embargo no hay que entenderla como ley escrita, sino más bien como la razón, el logos, que vive en el alma del gobernante y jamás debe abandonarlo"

A partir de esa mirada de las relaciones de poder, el "énfasis de la educación y la práctica ciudadana lograría la "acción social consensuada", en otras palabras, que se procuren factores sociales básicos del todo nación, si las vertientes del conglomerado humano solicita del momento un cambio o transformación de las entidades e imaginarios prefijados como modos de vida en la sociedad de hoy. Si los ciudadanos o ciudadanas, de la República Bolivariana de Venezuela por ejemplo, van a ser capaces de actuar para el "cambio" a nivel social, necesitan entonces tener marcos conceptuales-cognitivos que sean consistentes con tal fin y con las perspectivas en las que se de "igual peso integral" a las fuerzas sociales, políticas sociales, y económicas. A su vez, luce necesario conocer y comprender la pertinencia socio-histórica del sistema político local, regional y nacional, ya que éste ayuda a tener claro los factores que fortalecen el desarrollo integral de la ciudadanía"44. La fortaleza de los espacios y las leyes se reivindican y cobra importancia las cosas que pertenecen a los hombres y mujeres de una RepúblicaEstado-Nación. Es claro que el "Arte de gobernar" resalta en una bidireccionalidad sustentada en las relaciones humanas con base en el "respeto y comprensión" al todo interactuante. En atención a esta relación, Foulcault (2005) ${ }^{45}$ enfatiza en los principios que rigen la "virtud" desde las acciones de racionalidad gubernamental, y al respecto profiere:

"Es sabida la importancia que toma el problema de la virtud de los emperadores, de su vida privada y de la manera en que saben dominar sus pasiones: se ve en ello la garantía de que sabrán poner por si mismo un límite al ejercicio de su poder político. Pero este principio vale para quienquiera que deba gobernar: debe ocuparse de si mismo, guiar su propia alma, establecer su propio

La percepción del mundo no solo hila lo tangible, los referenciales hilan también en lo humano, y por ello, el mundo del ser deriva también en sentimientos y sus múltiples relaciones. El "poder" se desfigura cuando no dibuja la esencia humana-

\footnotetext{
${ }^{43}$ (2005) FOUCAULT, Michel. Historia de la sexualidad 3-la inquietud de sí. Decimocuarta edición en español. Siglo XXI editores. México. Pág. 87

${ }^{44}$ (2009) MÁRQUEZ, Ysrael. Educación, Ciudadanía y Formación Ciudadana: Tendencias complejas hacia una configuración-humanística-sustentable. En Itinerarios de Investigación. Compilador Agustín Martínez. Programa de Estudios Postdoctorales. ISBN: 9789802880409. Universidad Nacional Experimental Simón Rodríguez. Núcleo Regional de Postgrado. Caracas. Venezuela (RB) Pàg.36.

${ }^{45}$ (2005) FOUCAULT, Michel. Historia de la sexualidad 3-la inquietud de sí. Decimocuarta edición en español. Siglo XXI editores. México. Pág. 87
} 
espiritual. Lo humano no solo son reglas hacia el otro, también lo es hacia si mismo. El "cuido de si" es también el cuido al otro. Es lo que Gadamer (1991) 46 define como la "comunicación humana". Sostiene el autor desde la visión del "juego humano" la relación con el otro se dibuja necesariamente con la participación en el movimiento del "juego" mismo y sus "artes". En el "juego" hay un "jugar con", esto es, jugadores y espectadores son parte del todo interrelacionado en norma y pasión. Se establece una vinculación interrelacional y comprensiva de respeto, significación y representación. La autorregulación se fortalece desde lo individual y lo colectivo en sentido de arte y razón como expresión de lo humano en correspondencia de una "ética relacional".

O en palabras del mismo Foucault (2005) ${ }^{47}$ la "determinación de la sustancia ética", aquella que se sostiene en la manera en que el individuo deba dar forma a tal o cual parte de si mismo como materia principal de su conducta moral. Se refiere a una práctica de la fidelidad en el estricto respeto a las prohibiciones y obligaciones en los actos mismos que uno realiza. El dominio de los deseos y pasiones es la fuerza para resistir las tentaciones y favorecerse a si mismo en el conjunto interrelacionante de un ente, una comunidad o sociedad especifica. La valoración a si mismo se conjuga en el otro, es la valoración de lo humano y el respeto a la humanidad y su perdurabilidad planetaria.

\section{Lo Ético-moral, Lo Educativo y Lo Formativo: hacia la configuración de una civilidad mundial}

En los precedentes textos se insertan aspectos preponderantes que delinean una relación múltiple entre educación, ética y acción social. La sociedad en tiempos de cambio necesita mirarse a si misma en el contexto de los asuntos globales. Edgar Morin (1999) ${ }^{48}$ en su libro "Tierra Patria" nutre su discurso desde la necesidad de convivencia humana en la nave planetaria, y al mismo tiempo, resalta la necesidad de que "la humanidad debe elaborar la corregulación de la biosfera terrestre. Se impone la doble conducción: Hombre/naturaleza; tecnología/ecología; inteligencia consciente/inteligencia inconsciente..." Maffesoli (2006) ${ }^{49}$, por otra parte, lo refuerza afirmando que es necesario insistir en la búsqueda de otra forma de socialización a propósito de los signos de un nuevo tiempo. El autor apoya un

\footnotetext{
${ }^{46}$ (1991) GADAMER, Hans-Georg. La Actualidad de lo Bello. Pensamientos Contemporáneos 15. Ediciones Paidòs. Barcelona, España. Pàg.68-69

${ }^{47}$ (2005) FOUCAULT, Michel. Historia de la Sexualidad. 2-el uso de los placeres. Décimo sexta edición en español. Siglo XXI Editores, S.A. México. Pág. 27.

${ }^{48}$ (1999) MORIN, Edgar. Tierra Patria. Ediciones Nueva Visión, SAIC. Buenos Aires, Argentina. Págs. 213-214.

49 (2006) MAFFESOLI, Michel. Una Mirada a la Violencia Social. Entrevista: Por Vicente Verdù. El País Semanal, 08-01-2006. Disponible en: http://es.geocities.com/sucellus25/3154.htm
} 
proceso orientado hacia el futuro de un nuevo "estar juntos" cuya orientación se entiende a disfrutar del "aquí y ahora" en un mismo "domus"; la casa de todos. Ambos estudiosos de los asuntos del hombre coinciden en la relevancia que tienen los aspectos socio-antropológicos y educativos en el contexto de la sustentabilidad socio-humana. Parece que esto es posible si se conjugan las voluntades humanas para entender que la Educación y la Formación Ciudadana son vitales para un país, región o el planeta en su todo interrelacional. Por consiguiente, las dimensiones "educación" o "formación" se entrelazan en la malla social y educativa en múltiples vertientes del acontecer humano.

La prescripción etimológica de los términos en cuestión podría ayudar a su comprensión en el contexto del discurso mismo. Por consiguiente, desde esta línea argumentativa, la palabra "educación" deriva de educar del latín educāre que significa dirigir, encaminar, doctrinar, desarrollar o perfeccionar las facultades intelectuales y morales del niño o del joven por medio de preceptos, ejercicios, o ejemplos. Esta noción básica se vincula de alguna manera con la connotación del vocablo "formación" que se deriva del latín formatioo, -ōnis y su alcance significativo se refiere a la acción y efecto de "formar o formarse" (del latín formāre), es decir, dar forma a algo, criar, educar, adiestrar, adquirir más o menos desarrollo, aptitud o habilidad en lo físico o en lo moral, (Real Academia Española, 2007) ${ }^{50}$

La connotación que se deriva de los vocablos "educación" y "formación" actualmente transciende los límites mismos de los pensamientos tradicionales y clásicos. Las complejidades de la época obligan a pensar en el ajuste nocional de los mismos así como de los procesos que los vinculan. En el entendido que ambos vocablos establecen una relación en la cual la formación es el proceso consolidativo del proceso educativo en tiempo permanente de la vida. Zarzar Charur (2003) ${ }^{51}$ cuando aproxima definir el vocablo "Formación" en el contexto educativo indica que "es un concepto tan rico y complejo que es imposible abarcarlo por completo en una sola definición". Ya que "en el campo educativo, cuando se utiliza el concepto, casi siempre se emplea junto a con algún adjetivo o algún complemento con el fin de delimitar el ámbito al que hace referencia" (ej. formación docente, formación profesional, formación cívica, formación socialista)". Por otra parte, el vocablo Educación descansa en la analogía con el cultivo de las plantas o de los animales. Su significación connota "producir un recto crecimiento,

\footnotetext{
50 (2005) REAL ACADEMIA ESPAÑOLA. Consulta en línea. DICCIONARIO DE LA LENGUA ESPAÑOLA - Vigésima segunda edición. Disponible: http://www.rae.es/. [Consulta: 2007, febrero 10].

${ }^{51}$ (2003) ZARZAR CHARUR, Carlos. La Formación Integral del Alumno: qué es y cómo propiciarla. Fondo de Cultura Económica México. México. Pàg. 25.
} 
mediante un cuidado o tratamiento adecuado" ${ }^{52}$ Estas distinciones conceptuales indudablemente colocan de relieve la importancia dimensional de su esencia en lo referido a lo humano-social-relacional universal. Esta da significación implícita a la sustentabilidad en el marco connotativo como expresión de los escenarios vivenciales y convivenciales. Lo que implica que cada ser humano cognitivamente proyecta sus acciones a lo "estratégico" 53 desde las vivencias en modos de aprendizajes individuales aplicables a los modos de vida cotidianas.

Cejas y Grau (2007) ${ }^{54}$ consideran fundamental lo "estratégico" como valor individual o colectivo en el ámbito social. Y su especificidad la aplican al campo de las competencias profesionales o de gestión de Recursos Humanos. Este enlace se bidirecciona en términos de "formación como factor estratégico". Esta sentencia como base formativo-gerencial la definen como "un proceso que debe estar siempre vinculado a la mayor calidad de vida" de los actores intervinientes en una organización, comunidad o en una sociedad especifica. $Y$ por lo tanto, sus directrices se perfilan hacia la consolidación de las "competencias" de los actores con la finalidad de "facilitar su adaptación ante los cambios" que le devienen de su entorno.

En el marco de este complejo camino de muldimensionalidad connotativa los argumentos de Adela Cortina $(1997)^{55}$ se perfilan estimulantes cuando reflexiona en torno a los componentes éticos, morales y ciudadanos. La formación de ciudadanos y ciudadanos en la actualidad no se presenta en términos de sutilezas constructivas. La filosofa en referencia señala que la sociedad de hoy y particularmente el estado deben necesariamente considerar la complejidad de los asuntos ciudadanos. Este último tiene la obligación de centrarse en los elementos éticos. Agrega que un "Estado Social de Derecho consiste en incluir en el sistema de derechos fundamentales, no solo las libertades clásicas, sino también los derechos económicos, sociales y culturales".

52 (1977) NATORP, Paul. Curso de Pedagogía, Primera Parte. Fundamentación. En: Teoría de la Educación y Sociedad. \# 48. Por: Natorp, Dewey, Durkein. Centro editor de América Latina. Buenos Aires, Argentina. Pàg.25.

${ }^{53}$ (2006) MORIN, Edgar y Otros. plantean la necesidad de establecer ejes estratégicos educativos como directrices para una acción ciudadana. "La educación planetaria debe propiciar una mundología de la vida cotidiana". En: Educar en la Era Planetaria. Editorial Gedisa. Barcelona España. Pág. 123.

${ }^{54}$ (2007) CEJAS, Magda y GRAU, Carlos. Formación de los Recursos Humanos en las Organizaciones Empresariales. Una visión Teórica-epistemológica desde la Formación por Competencias. Fondo Editorial Tropykos, FACULTAD DE Ciencias Económicas y Sociales-Centro de Investigaciones en Sociedad-Economía y Transcomplejidad. Universidad de Carabobo.

Venezuela.

${ }^{55}$ (1997) CORTINA, Adela. Ciudadanos del Mundo. Hacia una Teoría de la Ciudadanía. Alianza Editorial. Madrid. Pàg.77. 
Parece fundamental repensar o redefinir los elementos claves que orientan el comportamiento socio-humano cuando se trata de la sustentabilidad social y sus vinculaciones que se engranan al "Estado-república" o "Nación". Lo humano se inserta con gran importancia tanto teórica como empíricamente. Su trascendencia va más allá de los límites estado-nación. La globalidad de los fenómenos coloca entredicho las particularidades de las sociedades. La ética se universaliza en la medida que se profundizan los mecanismos de interrelación o comunicación humana. Así, los "bienes" se universalizan y por ello que la sociedad en su conjunto bien articulado propulsa el disfrute desde lo socialmente consensuado. El alimento, el vestido, la vivienda, la educación, la cultura o el sentimiento se "consolida" desde el ámbito interrelacional humano. Cortina (2002) ${ }^{56}$ sostiene que estos son producto de personas que viven en sociedad y por lo tanto, son bienes sociales. Bienes que en consecuencia, deben ser también socialmente distribuidos para que podamos llamar a esa distribución justa.

La complejidad del término "Justicia" consolida la sociedad, su intrínseco sentido humano mueve los cimientos de la humanidad en tanto satisfacción y bienestar social. Russel (2002) ${ }^{57}$ indica que el termino debe ser entendido como "lo que la mayoría de la gente cree que es justo, o más bien, para evitar el circulo vicioso, ese sistema que produce el menor motivo de queja comúnmente reconocido...lo que es siempre igual en todas las comunidades es que el sistema justo es el que produce la menor cantidad de descontento". Es decir, se perfila la necesidad de los principios de la "contextualidad constructiva y consensual", además de la dimensión ética y moral, que requiere la actividad humana en estos tiempos. "Estos elementos pudieran estar movidos por las fuerzas internas y externas del sistema societal en su conjunto, las cuales se expresarían interactivamente hacia el logro de la equidad, justicia, libertad y amor; valores éstos de primer orden para la concienciación y la acción colectiva e individual" ${ }^{28}$.

Las acciones políticas en su conjunto también tendrán que ser reintepretadas y recontextualizadas en atención a los principios de una ética enmarcada en los principios humanos y sociales universales. Así, la importancia de la actividad política y sus actores se interconectan desde nodos con bases ético-morales con fines comunes. Por ejemplo, el pensamiento en la sociedad griega valoró las

${ }^{56}$ (2002) CORTINA, Adela. Por una Ética del Consumo. Editorial Taurus. Madrid, España. Disponible:http://www.aloj.us.es/vmanzano/pdf/resumen/cortina.pdf. [Consulta: 2008, Octubre, 05].

${ }^{57}$ (2002) RUSSEL, Bertrand. Sociedad Humana. Ética y Política. Ediciones Cátedra. Colección Teorema. Madrid, España. Pág. 37.

58 (2009) MÁRQUEZ, Ysrael. Educación, Ciudadanía y Formación Ciudadana: Tendencias complejas hacia una configuración-humanística-sustentable. En Itinerarios de Investigación. Compilador Agustín Martínez. Programa de Estudios Postdoctorales. ISBN: 9789802880409. Universidad Nacional Experimental Simón Rodríguez. Núcleo Regional de Postgrado. Caracas. Venezuela (RB) Pág.36. 
actividades cívicas y su vinculación con la dualidad ético-moral. Esto representó un verdadero oficio para las actividades de los ciudadanos y ciudadanas. Esta manera de pensar la resalta Foucault (2005) ${ }^{59}$ a propósito del "juego político" y "el cultivo de si" en sociedad:

"La 'actividad política y actor moral' era uno de los temas más constantes del pensamiento político griego que en una ciudad no podría ser feliz y bien gobernada sino a condición de que sus jefes fueran virtuosos, e inversamente, que la buena constitución de la ciudad y unas buenas leyes sabias eran factores decisivos para la conducta justa de los magistrados y de los ciudadanos. La virtud del gobernante, en todo pensamiento político de la época imperial, es considerada siempre como necesaria, pero por razones un poco diferentes. No es como expresión o efecto de la armonía del conjunto como esta virtud es indispensable, sino porque, en el arte difícil de gobernar, en medio de tantas emboscadas, el gobernante tendrá que guiarse por su razón personal: sabiendo conducirse bien es como sabrá conducir a los demás como es debido"

Es por ello, que los elementos vinculantes a las dimensiones educativas pasan por tomar conciencia en los procesos que acontecen a propósito de los fenómenos socio-humanos-planetarios. A los ciudadanos y ciudadanos, en el amplio sentido, se les confiere la condición humana en trascendencia natural y valoración universal. Por lo tanto, los entes responsabilizados de la gestión socio-escolarciudadana serán ejemplo de ciudadanía institucional al conferir las virtudes a su entorno. La dignidad del otro resulta potenciada cuando quien ostenta ser "servidor de bienes" conjuga esfuerzos para atender y otorgar "felicidad". En esa dirección de la "alteridad", Paulo Freire $(1999)^{60}$ sostiene que hoy las relaciones entre los hombres y mujeres se miran con un mayor sentido ético-antropológico. "El amor, la amistad, la transparencia, la voluntad política" las presenta como categorías vivenciales en nuestros días. Y en este sentido, las dimensiones educativas y formativas en el marco de sus vinculaciones ciudadanas se singularizan también en "vida y cuerpo". Es decir, se entiende que lo humano prevalece; el individuo-el cuerpo también forman parte del todo. "Hay mucha sensualidad que el cuerpo guarda y explícita, unido incluso a la capacidad cognoscente". Una visión educativa de ciudadanía que se sustenta en la principios de una "Antropoètica" propulsa también los valores humanos visto como honestidad, solidaridad, respeto, amor. La educación en los términos de integralidad y complejidad socio-antropológica necesariamente conducirá reflexiones hacia los contenidos de una "sociedad educadora" que tome en cuenta

\footnotetext{
59 (2005) FOUCAULT, Michel. Historia de la Sexualidad 3-la inquietud de sí. Decimocuarta edición en español. Siglo XXI editores. México. Pág. 86

${ }^{60}$ (1999) FREIRE, Paulo. La Educación en la Ciudad. Siglo XXI editores. Segunda Edición. México. Pág. 107.
} 
la dimensión subjetiva, poética y afectiva del ser humano, una "Antropoética Educativa" ${ }^{\prime 1}$.

\section{Algunas destellantes Reflexiones en la puerta de salida...}

La sociedad desde tiempos remotos se ha visto impactada por fenómenos tanto naturales como producto de las mismas interacciones humanas. Desde luego, cada momento del devenir humano dibuja sus propias estrategias vivenciales y conjuga sus acciones a favor de rediseñar su propia sustentabilidad en el escenario particular. En este sentido, la reingeniería social toma su base en las mismas interrelaciones de su amplia concepción comunicacional. Esta ya no se limita solo a fundarse en los ámbitos locales, sino que extienden sus acciones fuera de sus fronteras y toma igualmente las claves para empoderarse y accionar en su propio ámbito. En esta esfera de la sociabilidad significativa de los modelos de asentamiento de la población, Castells $(2001)^{62}$ señala que "la gente no construye su significado en la sociedades locales, no porque carezca de raíces territoriales sino porque selecciona sus relaciones sobre la base de sus afinidades". De esta manera, la arquitectura de una sociedad soporta las "dinámicas naturales" o aquellas impulsadas por fenómenos propios de los desajustes estructurales de la misma sociedad y de la misma humanidad. La invulnerabilidad de la sociedad actual se hace presente con bases de una red de cristal. El ciudadano y la ciudadana, actores fundamentales de los escenarios sociales, necesitan de consolidadas "estrategias convivenciales" para soportar los embates de los entornos complejos y dinámicos. Cortina (1997) ${ }^{63}$ enfatiza que:

"la racionalidad de la justicia y el sentimiento de pertenencia a una comunidad concreta han de ir a la par, si deseamos asegurar ciudadanos plenos y a la vez una democracia sostenible. La ciudadanía es un concepto mediador porque integra exigencias de justicia y a la vez hace referencia a los que son miembros de la comunidad, une la racionalidad de la justicia con el calor del sentimiento de pertenecia".

La "sustentabilidad" entendida tanto como la "perdurabilidad" y "fuerza de soporte" signa una época en la diversidad dimensional del escenario mundial. Los ciudadanos y ciudadanas por su configuración bio-psico-social-planetaria tendrán

\footnotetext{
${ }^{61}$ (2005) MÁRQUEZ, Ysrael. Educación y Ciudadanía: Una visión antropoética postmoderna en el contexto del sistema educativo venezolano. Tesis Doctoral no publicada. Núcleo Regional de Postgrado Caracas. Universidad Experimental Simón Rodríguez. Caracas.

62 (2001) CASTELLS, Manuel. La Galaxia Internet. Primera edición. Plaza \& Janés Editores S.A. Traducción Raúl Quintana. Barcelona España. P. 147.

63 (1997) CORTINA, Adela. Ciudadanos del Mundo. Hacia una Teoría de la Ciudadanía. Alianza Editorial. Madrid. Págs. 34-35.
} 
la responsabilidad de interpretar y comprender los signos epocales para generar los cambios requeridos para un mundo donde los valores democráticos y humanos sean las claves de la sustentabilidad mundial. La ética y la moral conducen hacia el equilibrio de las relaciones humanas. Razón y sentimiento buscan sus verdaderos asentamientos en las virtudes sociales y humanas. Ante la complejidad de los escenarios y los retos que se perfilan en la sociedad globalizada, los ciudadanos y ciudadanas tendrán que apelar a la total satisfacción de los buenos deseos. "Los deseos composibles ${ }^{64}$ son preferibles como medios. El amor es preferible al odio, la cooperación a la competición, la paz a la guerra" 65 La Formación como proceso vinculante y permanente del proceso educativo eleva sus buenos lazos a favor de amalgamar ciudadanos y ciudadanas del mundo; un desarrollo humano verdaderamente sustentable. En este sentido, el proceso comunicativo desde el pensamiento socio-humano puede construir complejidades pero puede delinear al mismo tiempo las acciones en el cualquier ámbito de su quehacer con el fin último de sostener el equilibrio en su propio entorno. Los escenarios de interacción educativa y formativa deben perfilarse con "la misión de transmisión de estrategias para la vida. La transmisión necesita, evidentemente, la competencia, pero también requiere, además, una técnica y un arte"66.

Con base en las propias interpretaciones del hilo discursivo en su conjunto, se puede decir que existe una importante tendencia en algunos países latinoamericanos (Ej. Ecuador, Bolivia, Nicaragua, Venezuela) a considerar también la importancia de los conceptos relacionados con la noción de "desarrollo endógeno" y "participación integracionista" como fundamentos para proponer modelos de desarrollo socio - económico regional y locales basados en la concertación social-comunitaria en los términos de una "visión socialista" de los sistemas educativos y formativos en general. A bien y desde esta perspectiva, la proyección de la sociedad Latinoamérica y del Caribe en su propio ámbito interactuante deberá prestarle especial atención a la "concertación o consenso" sobre los recursos integrales de definición "endógena" y de mayor prioridad "estratégico-convivencial" desde el todo vinculante. Esto permitiría realizar

\footnotetext{
${ }^{64}$ Bertrand Russel se apoya en las ideas del Filósofo, Jurista, Político y Matemático Gottfried Wilhelm von Leibniz quien nació el 1 de julio de 1646 en Leipzig, Alemania. Descubrió el sistema binario y el cálculo infinitesimal. Leibniz formuló algunos deseos y aspiraciones ampliamente sentidos en su tiempo, con lo que se convirtió en vocero de sentimientos compartidos. El vocablo "Composible" lo desde la concepción tradicional: "es posible lo que no es contradictorio; por ejemplo, un círculo cuadrado es imposible porque justamente hay contradicción entre la circularidad y el cuadrado". Disponible: http://www.hottopos.com/mp2/leibniz.htm.

${ }^{65}$ (2002) RUSSELL,Bertrand. Sociedad Humana. Ética y Política. Ediciones Cátedra. Colección Teorema. Madrid, España. Pág. 61.

${ }^{66}$ (2006) MORIN, Edgar y Otros. Educar en Ia Era Planetaria. Editorial Gedisa. Barcelona, España. Pág. 122.
} 
articulaciones concretas entre los agentes que definan el camino hacia la conducción del "todo"; redefinido en destino configurado como parte de un proyecto común ampliamente fortalecido desde los discursivos principios hilvanados. La correcta combinación de esfuerzos de las "familias" y de los "Estados-gobiernos" deberá ser un elemento central de un significativo "contrato social" global. "Todo ello con especial énfasis en los procesos de educación y formación del ciudadano(a) de la neo-sociedad deseada" ${ }^{67}$.

En síntesis, se trata de impulsar los mecanismos y estrategias socio-políticas orientadas a consolidar procesos educativos y formativos desde lo verdaderamente humano, así, la principal función del ciudadano o ciudadana en la esfera societal será formar seres humanos plenos, capaces de utilizar sus potenciales a favor de espacios democráticos, hombres y mujeres "capaces de potenciar una masa crítica y creadora de sus capacidades, es decir, que no sean simplemente personas con una destreza laboral determinada sino personas capaces de desarrollar su humanidad y de reconocerla y potenciarla en otros también"68. Se trata en fin de potenciar también procesos socio-educativos fundamentados en la ampliación de horizontes mediante el cual se le de valor a lo cotidiano y sus implicaciones político sociales. Es decir, potenciar la comprensión desde la espiritualidad para una cultura de la paz y la convivencia en la noción de una ciudadanía mundial y de la fraternidad.

"¿algún acercamiento al sentido civilizacional?" En favor de la Instruccion jeneral no hay raciocionio accesorio, ni argumento que no sea concluyente. Instruccion Social, para hacer una nacion prudente: Corporal, para hacerla fuerte: Técnica, para hacerla experta: y Científica para hacerla pensadora No será ciudadano el que para el año de tantos no sepa leer y escribir (han dicho los Congresos de América) está bueno; pero no es bastante: Ideas!, Ideas! primero que Letras.

${ }^{67}$ (2009) MÁRQUEZ, Ysrael. Educación, Ciudadanía y Formación Ciudadana: Tendencias complejas hacia una configuración-humanística-sustentable. En Itinerarios de Investigación. Compilador Agustín Martínez. Programa de Estudios Postdoctorales. ISBN: 9789802880409. Universidad Nacional Experimental Simón Rodríguez. Núcleo Regional de Postgrado. Caracas. Venezuela (RB). Pág. 37.

${ }^{68}$ (2004) SAVATER, Fernando. Democracia y Ética. Entrevista realizada por el Dr. Bienvenido Argueta Hernández. Universidad de Costa Rica. Facultad de Educación. Instituto de Investigación para el mejoramiento de la Educación Costarricense. Disponible: http://revista.inie.ucr.ac.cr/articulos/1-2004/archivos/entrevista.pdf. [Consulta: 2008, Febrero 25] 
Simón Rodríguez ${ }^{69}$

${ }^{69}$ SOCIEDADES AMERICANAS EN 1828 - LUCES Y VIRTUDES SOCIALES. VERSIÓN HTML V.1.0 - JULIO 2002 Transcripción en HTML, Versión 1.0 (Julio 2002), del facsímil de la Edición de Valparaíso, 1840, en la reproducción de la edición del Congreso de la República de Venezuela, 1973. Texto electrónico preparado por: Raúl Escalante. Disponible: http://mipagina.cantv.net/t6435bm/SA Valp/SA Valp 33 46.html\#primera. Pág. 36 